\title{
Ultrasound features of medullary thyroid cancer as predictors of biological behavior
}

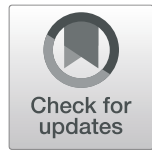

Jingzhu Zhao ${ }^{1}$, Xiangqian Zheng ${ }^{1}$, Ming Gao ${ }^{1 *} \mathbb{D}$, Sheng Zhang ${ }^{2}$, Xinwei Yun ${ }^{1}$, Jiadong Chi $^{1}$ and Guangwei Xu ${ }^{1}$

\begin{abstract}
Background: Medullary thyroid cancer (MTC) has more aggressive behavior and poor prognosis. Ultrasound (US) has facilitated the qualitative diagnosis of thyroid nodules, however, some MTC may be diagnosed as a benign nodule on ultrasound because ultrasound features of malignancy are lacking. The aim of the study was to investigate the association between ultrasound features and biological behavior of MTC.

Methods: Ultrasound findings and medical records of patients with MTC between Jan 2015 to Jun 2017 were retrospectively reviewed at Tianjin Medical University Cancer Institute and Hospital. MTC were categorized using modified TI-RADS classification, then were classified as "malignant" (m-MTC) or "US-low-suspicious" (I-MTC). We compared the biological behavior between the two groups, and further analyzed the risk factors for the recurrence.

Results: A total of 78 patients were enrolled, of which 55 m-MTC (70.5\%) and 23 I-MTC (29.5\%) were identified. The N staging of the m-MTC was significantly higher than that of I-MTC $(P=0.000)$. The preoperative serum Ct level in m-MTC were significantly higher than that of I-MTC $(P=0.035)$. Biochemical cure were more frequent in I-MTC than that of m-MTC $(P=0.002)$. Disease recurrence rates were $19.7 \%$ (14 of 71). Disease recurrence was more frequent in m-MTC than that of I-MTC $(P=0.013)$. Disease recurrence was positively associated with extrathyroid extension $(P=0.047), \mathrm{N}$ staging $(P=$ $0.003)$, preoperative serum $C t$ level $(P=0.009)$ and negatively associated with biochemical cure $(P=0.000)$. In multivariable Cox regression analysis, extrathyroid extension and biochemical cure were independent risk factors for recurrence of MTC.

Conclusions: L-MTC has a more indolent character than m-MTC. The extrathyroid extension and biochemical cure were independent risk factors for recurrence of MTC.
\end{abstract}

Keywords: Medullary thyroid cancer, TI-RADS, Ultrasound, Serum Ct, Recurrence

\section{Background}

Medullary thyroid cancer (MTC) originates from thyroid $\mathrm{C}$ cells and accounts for about $5 \%$ of thyroid malignancy [1]. MTC has more aggressive behavior than differentiated thyroid cancers and up to $13.4 \%$ of thyroid cancer-related deaths due to MTC $[2,3]$. Therefore, early diagnosis of MTC is important for improving long-term prognosis.

\footnotetext{
*Correspondence: headandneck15@aliyun.com

'Departments of Thyroid and Neck Tumor, Tianjin Medical University Cancer Institute and Hospital, National Clinical Research Center for Cancer, Key Laboratory of Cancer Prevention and Therapy, Tianjin, Tianjin's Clinical Research Center for Cancer, Tianjin 300060, P. R. China

Full list of author information is available at the end of the article
}

Ultrasound is the crucial tool for the preliminary evaluation of thyroid nodules $[4,5]$. Several classification systems have been proposed in order to standardize the assessment of thyroid nodules using ultrasonography $[6,7]$. Most classification systems, including TI-RADS, are primarily applicable to papillary thyroid carcinoma. There was only a few studies researched the application of TI-RADS in assessing MTC [8, 9], and the applicability of TI-RADS in MTC patients is still not sufficient.

Therefore, the aim of our study was to more fully investigate the ultrasound features of MTC and to analyze the association ultrasound features with its biological behavior. 


\section{Materials and methods Patients}

There were 86 patients who had been operated for MTC over the period from Jan 2015 to Jun 2017 at Tianjin Medical University Cancer Institute and Hospital. The preoperative diagnosis primarily based on high serum calcitonin levels and preoperative neck ultrasonography. 8 patients were excluded as they had undergone thyroid excision in other hospital. Finally, 78 patients were enrolled in the study. This study was approved by the ethics committee of our hospital, and informed consent was obtained from all patients.

\section{Sonographic image analysis according to modified TI-RADS} Ultrasound examinations were performed with a 5$12 \mathrm{MHz}$ linear array transducer (iU22; Philips Diagnostic Ultrasound System, Bothell, WA). Ultrasound images of each thyroid nodule were recorded in our institutional database. Retrospective review of ultrasound images was performed by two experienced reviewers. All reviewers were blinded to the clinical pathology results and categorized the nodules according to modified TI-RADS [9, 10].If the diagnosis were discordant, the third reviewer served to achieve consensus. In brief, nodules were categorized on ultrasound by composition, echogenicity, presence of calcification, margin, shape and vascularization according to the standard methodology from previously published reports $[9,10]$. The categories were as follows: TI-RADS 1: normal thyroid gland, no nodule, no need to follow. TI-RADS 2: benign (risk $=0 \%$ ), nodule without any of the six high suspicious ultrasound features, suggested follow-up every year. TI-RADS 3 (risk $\leq 5 \%$ ): probably benign, nodule with any one of the six high suspicious ultrasound features, suggested follow-up every 6 months or FNAB if necessary. TI-RADS 4: suspicious malignant, 4a: nodule with any two or three of the six high suspicious ultrasound features, (risk range, 6 to 45\%); 4b: nodule with any four of the six high suspicious ultrasound features, (risk range, 46 to $75 \%$ ); 4c: nodule with any five or six of the six high suspicious ultrasound features, (risk range, 76 to 95\%), suggested FNAB or surgery. TI-RADS 5: certainly malignant (risk >95\%), one or more suspect lymph node(s) were associated with a thyroid nodule, suggested surgery. TI-RADS 6: malignant (risk =100\%), nodule confirmed by cytology or pathology.

According to their ultrasound features, all nodules were categorized as "malignant" (m-MTC) or "US-lowsuspicious" (l-MTC). The m-MTC were included as TI-RADS 4b,4c,5,6, and the 1-MTC were included as TI-RADS 2,3,4a.

\section{Serum calcitonin levels}

All patients had values for serum calcitonin measured using chemiluminescent immumoassay (reference range, $<5 \mathrm{pg}$ / $\mathrm{mL}$ for women, $<8.4 \mathrm{pg} / \mathrm{mL}$ for men). The preoperative and postoperative calcitonin level were recorded. The level of serum calcitonin is greater than $50-100 \mathrm{pg} / \mathrm{mL}$, a diagnosis of MTC is common [11]. A biochemical cure was defined by a calcitonin level within the reference range.

\section{Statistical analysis}

All statistical analyses were performed using SPSS software (SPSS, Chicago, IL, USA). The clinicopathologic features of all patients were compared statistically between l-MTC and m-MTC. The Student's t-test was used for the continuous numerical variables. The Chi-square test was used for categorical variables. The multivariate logistic regression analysis to determine independent risk factors of recurrence. Time to recurrence was calculated from the date of first surgery until recurrence. The last follow-up time is Feb 10, 2020. A value of $P<0.05$ was considered statistically significant.

\section{Results}

The present study consisted of 78 patients (38 males and 40 females) with histologically proved MTC, and their mean age was $50.9 \pm 11.8$ years (range, $14-75$ years). 76 patients underwent thyroidectomy with lymph node dissection for detecting MTC, and the other two patients, misdiagnosed as benign nodule, underwent thyroidectomy without lymph node dissection. Preoperative serum Ct was available in all 78 cases, and postoperative serum Ct was available in 63 cases.

\section{Comparison of clinicopathologic features of patients with I-MTC or m-MTC}

According to the ultrasound criteria for risk evaluation, 23 out of 78 cases were classified as l-MTC [TI-RADS $2(n=$ 2, 2.6\%);TI-RADS $3(n=3,3.8 \%) ;$ TI-RADS $4 \mathrm{a}(n=18$, $23.1 \%)]$ and 55 out of 78 cases as m-MTC[(TI-RADS $4 \mathrm{~b}$ $(n=16,20.5 \%)$; TI-RADS $4 \mathrm{c}(n=7,9.0 \%)$; TI-RADS 5 $(n=32,41.0 \%)]$. The comparison of the clinicopathologic features of patients with 1-MTC and m-MTC was shown in Table 1. The proportion of female in l-MTC was higher than in $\mathrm{m}$-MTC $(P=0.010)$. The mean rank of preoperative $\mathrm{Ct} /$ tumor size in $\mathrm{m}-\mathrm{MTC}$ is larger than that in 1 $\operatorname{MTC}(P=0.042)$. Cervical lymph node metastasis (central lymph node metastasis $P=0.000$, lateral lymph node metastasis $P=0.004$ and $\mathrm{N}$ staging $P=0.000$ ) were more frequent in $\mathrm{m}$-MTC than that of 1-MTC. The preoperative serum Ct level in m-MTC is higher than that in l-MTC $(P=0.035)$. The proportion of biochemical cure in 1-MTC was significantly higher than in $\operatorname{m-MTC}(P=0.002)$. The other variables, such as age, tumor size, multifocality, extrathyroid extension, $\mathrm{T}$ staging and $\mathrm{M}$ staging did not show a significant difference between the two groups. 
Table 1 Comparison of clinical characteristics of patients with I-MTC and m-MTC

\begin{tabular}{|c|c|c|c|c|}
\hline Variable & $\mathrm{N}$ & $\begin{array}{l}\text { I-MTC } \\
(n=23)\end{array}$ & $\begin{array}{l}\text { m-MTC } \\
(n=55)\end{array}$ & $P$ \\
\hline Age (years) & & $47.0 \pm 14.8$ & $52.6 \pm 10.0$ & $0.114^{a}$ \\
\hline Preoperative Ct/tumor size $(\mathrm{pg} / \mathrm{mL} / \mathrm{mm})$ & & 31.43 & 42.87 & $0.042^{b}$ \\
\hline Gender & & & & 0.010 \\
\hline Female & 40 & $17(73.9)$ & $23(41.8)$ & \\
\hline Male & 38 & $6(26.1)$ & $32(58.2)$ & \\
\hline Tumor size $(\mathrm{cm})$ & & $1.70 \pm 1.52$ & $1.75 \pm 1.21$ & 0.910 \\
\hline$\leq 1$ & 30 & $12(52.2)$ & $18(32.7)$ & 0.107 \\
\hline$>1$ & 48 & $11(47.8)$ & $37(67.3)$ & \\
\hline Multifocality & & & & 0.843 \\
\hline Yes & 25 & $7(30.4)$ & $18(32.7)$ & \\
\hline No & 53 & $16(69.6)$ & $37(67.3)$ & \\
\hline Extrathyroid extension & & & & 0.892 \\
\hline Yes & 45 & $13(56.5)$ & $32(58.2)$ & \\
\hline No & 33 & $10(43.5)$ & $23(41.8)$ & \\
\hline Central lymph node metastasis ${ }^{c}$ & & & & 0.000 \\
\hline Yes & 35 & $2(9.5)$ & $33(60.0)$ & \\
\hline No & 41 & 19 (90.5) & $22(40.0)$ & \\
\hline Lateral lymph node metastasis $^{d}$ & & & & 0.004 \\
\hline Yes & 30 & $1(20.0)$ & $29(12.1)$ & \\
\hline No & 8 & $4(80.0)$ & $4(87.9)$ & \\
\hline Preoperative Ct level (pg/mL) & & & & 0.035 \\
\hline$\leq 100$ & 19 & $10(43.5)$ & $9(16.4)$ & \\
\hline $100-1000$ & 31 & $6(26.1)$ & $25(45.4)$ & \\
\hline$>1000$ & 28 & $7(30.4)$ & $21(38.2)$ & \\
\hline Biochemical cure ${ }^{e}$ & & & & 0.002 \\
\hline Yes & 39 & $18(90.0)$ & $21(48.8)$ & \\
\hline No & 24 & $2(10.0)$ & $22(51.2)$ & \\
\hline T staging & & & & 0.892 \\
\hline $\mathrm{T} 1+\mathrm{T} 2$ & 33 & $10(43.5)$ & $23(41.8)$ & \\
\hline $\mathrm{T} 3+\mathrm{T} 4$ & 45 & $13(56.5)$ & $32(58.2)$ & \\
\hline M staging & & & & 1.000 \\
\hline M1 & 4 & $0(0.0)$ & $4(7.3)$ & \\
\hline MO & 74 & $23(100.0)$ & $51(92.7)$ & \\
\hline $\mathrm{N}$ staging & & & & 0.000 \\
\hline NO & 35 & $20(87.0)$ & $15(27.3)$ & \\
\hline N1a & 13 & $2(8.7)$ & $11(20.0)$ & \\
\hline $\mathrm{N} 1 \mathrm{~b}$ & 30 & $1(4.3)$ & $29(52.7)$ & \\
\hline
\end{tabular}

${ }^{a}$ t test; ${ }^{b}$ Mann-Whitney $\mathrm{U}$ test; ${ }^{\mathrm{c}} 2$ patients underwent thyroidectomy without lymph node dissection; ${ }^{\mathrm{d}}$ Only 38 patients were performed lateral lymph node dissection; ${ }^{\text {e }}$ Postoperative serum $\mathrm{Ct}$ is available in 63 cases

The univariate and multivariate analysis of recurrence 4 patients had underwented palliative surgery, and 3 patients were detected distant metastasis when initial surgery. So 7 patients were not included in the recurrence analysis. Median follow-up time is 35(1-69) months. In the overall analysis of MTC, disease recurrence rates were $19.7 \%$ (14 of 71 ). The univariate analysis of recurrence was shown in Table 2.

Disease recurrence was negatively associated with biochemical $\operatorname{cure}(P=0.000)$, and positively associated 
Table 2 The univariate analysis for recurrence in MTC patients

\begin{tabular}{|c|c|c|c|c|}
\hline \multirow[t]{2}{*}{ Variable } & \multirow[t]{2}{*}{$\mathrm{N}$} & \multicolumn{2}{|l|}{ Recurrence } & \multirow[t]{2}{*}{$P$} \\
\hline & & No & Yes & \\
\hline Age (years) & & $49.5 \pm 12.1$ & $53.4 \pm 9.3$ & $0.266^{\mathrm{a}}$ \\
\hline Preoperative Ct/tumor size ( $\mathrm{pg} / \mathrm{mL} / \mathrm{mm})$ & & 32.15 & 51.68 & $0.002^{b}$ \\
\hline Gender & & & & 0.768 \\
\hline Female & 38 & $31(54.4)$ & $7(50.0)$ & \\
\hline Male & 33 & $26(45.6)$ & $7(50.0)$ & \\
\hline Tumor size $(\mathrm{cm})$ & & $1.48 \pm 0.96$ & $1.81 \pm 1.11$ & 0.271 \\
\hline$\leq 1$ & 30 & $26(45.6)$ & $4(28.6)$ & 0.247 \\
\hline$>1$ & 41 & $31(54.4)$ & $10(71.4)$ & \\
\hline Multifocality & & & & 0.917 \\
\hline Yes & 22 & $17(29.8)$ & $5(35.7)$ & \\
\hline No & 49 & $40(70.2)$ & $9(64.3)$ & \\
\hline Extrathyroid extension & & & & 0.047 \\
\hline Yes & 39 & $28(49.1)$ & $11(78.6)$ & \\
\hline No & 32 & $29(50.9)$ & $3(21.4)$ & \\
\hline Central node metastasis $^{c}$ & & & & 0.000 \\
\hline Yes & 30 & $18(32.7)$ & $12(85.7)$ & \\
\hline No & 39 & $37(67.3)$ & $2(14.3)$ & \\
\hline Lateral node metastasis $^{d}$ & & & & 1.000 \\
\hline Yes & 26 & $18(78.3)$ & $8(72.7)$ & \\
\hline No & 8 & $5(21.7)$ & $3(27.3)$ & \\
\hline T stage & & & & 0.166 \\
\hline $\mathrm{T} 1+\mathrm{T} 2$ & 32 & $28(49.1)$ & $4(28.6)$ & \\
\hline $\mathrm{T} 3+\mathrm{T} 4$ & 39 & $29(50.9)$ & $10(71.4)$ & \\
\hline $\mathrm{N}$ stage & & & & 0.003 \\
\hline NO & 33 & $32(56.1)$ & $1(7.1)$ & \\
\hline N1a & 12 & $7(12.3)$ & $5(35.7)$ & \\
\hline $\mathrm{N} 1 \mathrm{~b}$ & 26 & 18 (31.6) & $8(57.1)$ & \\
\hline Preoperative Ct level (pg/mL) & & & & 0.009 \\
\hline$\leq 100$ & 16 & $16(28.1)$ & $0(0.0)$ & \\
\hline $100-1000$ & 31 & $25(43.9)$ & $6(42.9)$ & \\
\hline$>1000$ & 24 & $16(28.1)$ & $8(57.1)$ & \\
\hline Biochemical cure ${ }^{e}$ & & & & 0.000 \\
\hline Yes & 39 & $37(78.7)$ & $2(15.4)$ & \\
\hline No & 21 & $10(21.3)$ & $11(84.6)$ & \\
\hline Classification of TI-RADS & & & & 0.013 \\
\hline I-MTC & 22 & 22 (38.6) & $0(0.0)$ & \\
\hline m-MTC & 49 & $35(61.4)$ & $14(100.0)$ & \\
\hline
\end{tabular}

${ }^{\mathrm{a} t}$ test; ${ }^{\mathrm{b}}$ Mann-Whitney $\mathrm{U}$ test; ${ }^{\mathrm{c}} 2$ patients underwent thyroidectomy without lymph node dissection; ${ }^{\mathrm{d}}$ Only 38 patients were performed lateral lymph node dissection; ${ }^{e}$ Postoperative serum $\mathrm{Ct}$ is available in 63 cases,and 3 of these patients had underwented palliative surgery

with extrathyroid extension $(P=0.047)$, central node metastasis $(P=0.000), \mathrm{N}$ staging $(P=0.003)$ and preoperative serum $\mathrm{Ct}$ level $(P=0.009)$. Disease recurrence was more frequent in $\mathrm{m}$-MTC than that of 1 -MTC $(P=0.013)$. There was no association in recurrence with gender, age, tumor size, multifocality and $\mathrm{T}$ staging. Furthermore, in multivariable Cox regression analysis, extrathyroid extension and biochemical cure were independent risk factors for recurrence of MTC (Table 3). Kaplan-Meier analysis showed that the mean recurrence-free time of 
Table $\mathbf{3}$ The multivariate analysis of clinicopathological features for recurrence in MTC patients

\begin{tabular}{|c|c|c|c|c|c|c|c|c|}
\hline \multirow[t]{2}{*}{ Variable } & \multirow[t]{2}{*}{ B } & \multirow[t]{2}{*}{ S.E. } & \multirow[t]{2}{*}{ Wald } & \multirow[t]{2}{*}{ df } & \multirow[t]{2}{*}{ Sig. } & \multirow[t]{2}{*}{$\operatorname{Exp}(B)$} & \multicolumn{2}{|c|}{ 95\% C.I. for $\operatorname{Exp}(B)$} \\
\hline & & & & & & & Lower & Upper \\
\hline Extrathyroid extension & 1.653 & 0.791 & 4.366 & 1 & 0.037 & 5.223 & 1.108 & 24.624 \\
\hline Biochemical cure & -1.913 & 0.785 & 5.947 & 1 & 0.015 & 0.148 & 0.032 & 0.687 \\
\hline
\end{tabular}

patients with extrathyroid extension was obviously shorter than that of patients without extrathyroid exten$\operatorname{sion}(P=0.002)$, and the mean recurrence-free time of patients with biochemical cure was obviously longer than that of patients without biochemical cure $(P=0.001)$ (Figs. 1 and 2).

\section{Challenge of diagnosis in I-MTC patients}

In the present study, 5 patients, who were categorized as TI-RADS 2 and 3, were eventually diagnosed with medullary thyroid cancer by histopathology (Fig. 3, in the red box). Immunohistochemical examination were performed in 5 patients, including Cal, TG, TTF1, Syn, Ki-67 and CK-pan. The preoperative serum $\mathrm{Ct}$ level of the 5 patients were $117 \mathrm{pg} / \mathrm{mL},>2000 \mathrm{pg} / \mathrm{mL}$, $20.9 \mathrm{pg} / \mathrm{mL}, \quad 960 \mathrm{pg} / \mathrm{mL}$ and $<2 \mathrm{pg} / \mathrm{mL}$, respectively (Table 4). Ultrasonic images of thyroid nodules were showed (Figs. 4, 5 and 6).

\section{Discussion}

The present results showed that TI-RADS effectively stratified the risk of malignancy in the group of MTC, providing a basis for further treatment. The biological characteristics of m-MTC differed from those of l-MTC. Lymph node metastasis were significantly more frequent in $\mathrm{m}$-MTC than that of 1-MTC. The level of serum calcitonin was significantly higher in m-MTC than that of 1-MTC. Furthermore, the proportion of biochemical cure in 1-MTC was significantly higher than in m-MTC.

Our study indicated that there were no obvious difference of mean diameter between l-MTC and mMTC. However, the previous study reported that 1MTC were significantly larger than m-MTC $[12,13]$. It may is because that 1-MTC may be diagnosed at a later stage than m-MTC because of their benign ultrasonographic features in published literature, and l-MTC might be diagnosed at early stage in our

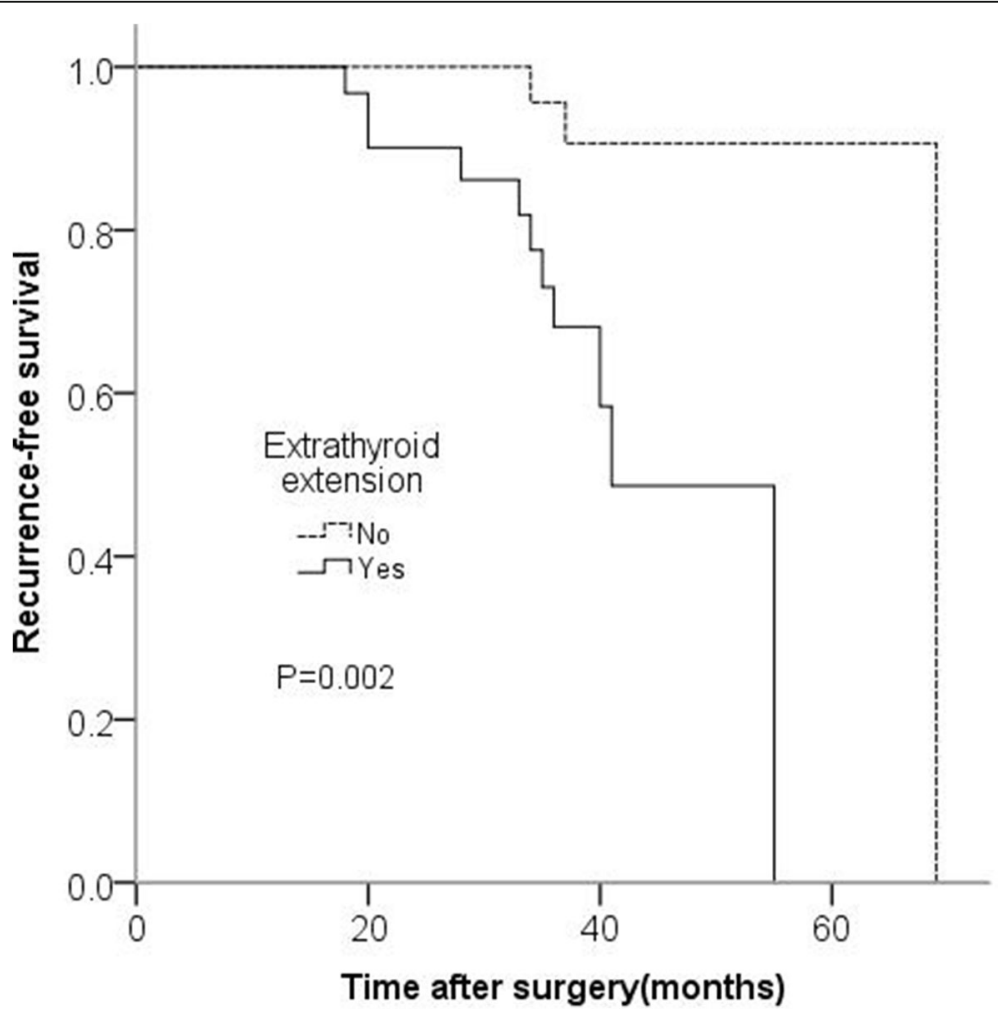

Fig. 1 Kaplan-Meier analysis of recurrence-free survival. The mean recurrence-free time of patients with extrathyroid extension was obviously shorter than that of patients without extrathyroid extension $\left(P_{\text {log-rank }}=0.002\right)$ 


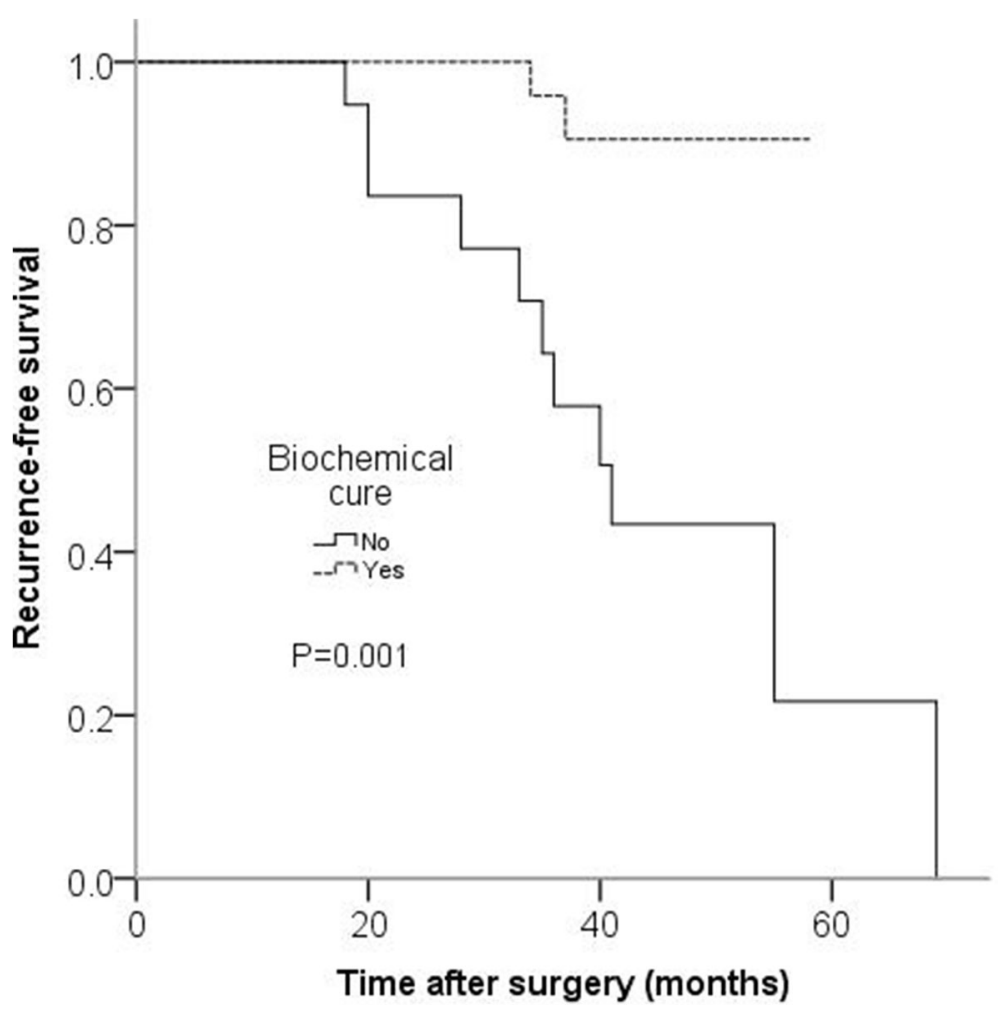

Fig. 2 Kaplan-Meier analysis of recurrence-free survival. The mean recurrence-free time of patients with biochemical cure was obviously longer than that of patients without biochemical cure $\left(P_{\text {log-rank }}=0.001\right)$

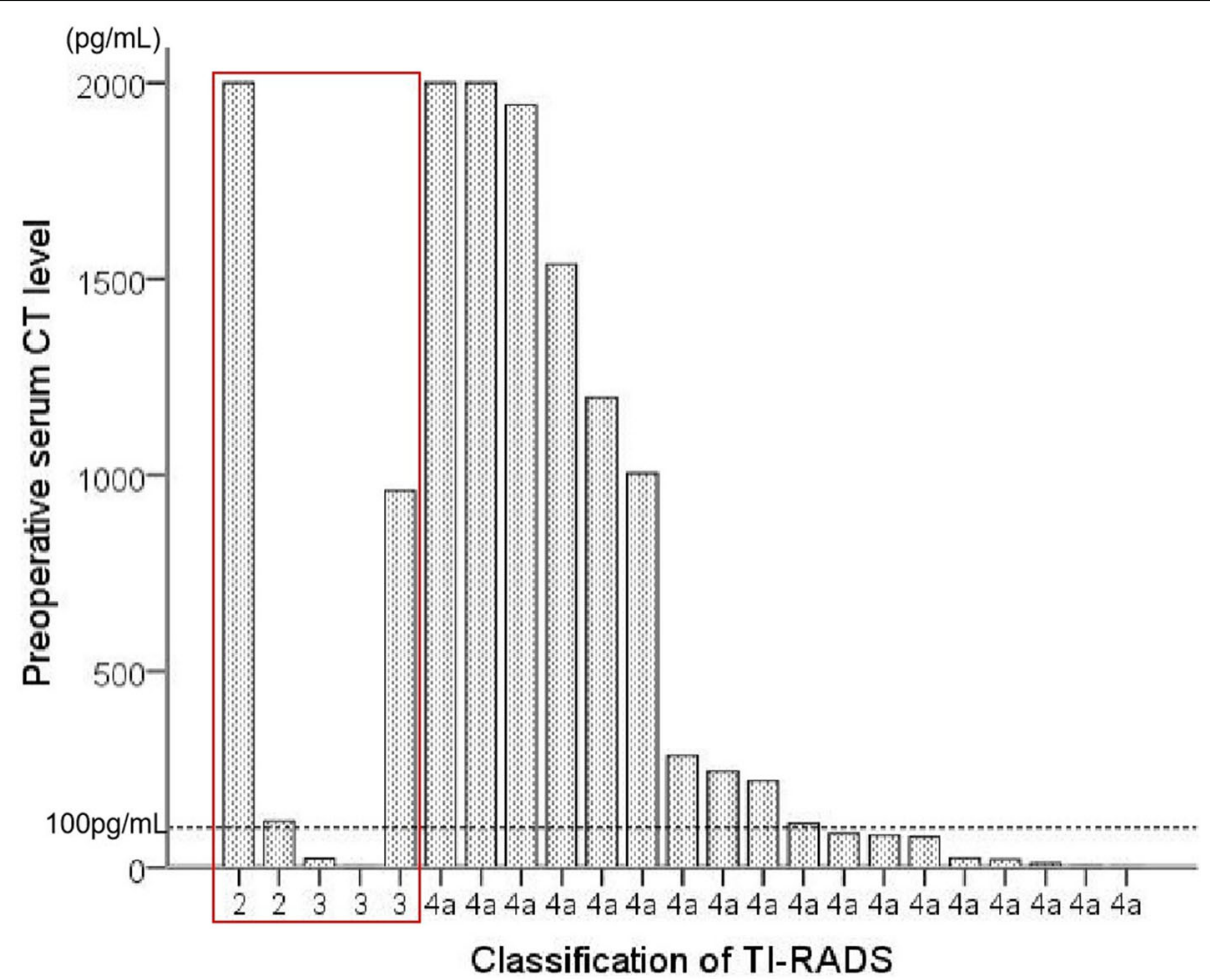

Fig. 3 The preoperation calcitonin level of 23 patients with I-MTC. 5 patients were categorized as TI-RADS 2 and 3 (in the red box) 
Table 4 A summary of clinicopathological features in 5 patients

\begin{tabular}{|c|c|c|c|c|c|c|c|c|}
\hline \multirow[t]{2}{*}{$\bar{N}$} & \multirow{2}{*}{$\begin{array}{l}\text { Graded by } \\
\text { TI-RADS }\end{array}$} & \multirow{2}{*}{$\begin{array}{l}\text { Serum Ct level } \\
(\mathrm{pg} / \mathrm{mL})\end{array}$} & \multicolumn{6}{|c|}{ Immunostaining } \\
\hline & & & $\overline{\mathrm{Cal}}$ & TG & TTF1 & Syn & Ki-67 & CK-pan \\
\hline 1 & 2 & 117 & + & - & + & NA & $2-3 \%$ & + \\
\hline 2 & 2 & $>2000$ & + & - & + & NA & $<1 \%$ & + \\
\hline 3 & 3 & 20.9 & + & - & + & + & NA & + \\
\hline 4 & 3 & 960 & + & - & + & + & $<1 \%$ & + \\
\hline 5 & 3 & $<2$ & + & - & + & - & NA & - \\
\hline
\end{tabular}

NA not available

hospital because of routine measurement of serum $\mathrm{Ct}$ in evaluating thyroid nodular.

In the previous studies, approximately one-third of MTC patients had benign ultrasonic characteristics [12-15], which mainly include solid, hypoechogenicity, ovoid to round in shape and smooth margin. The results of our study showed that based on the modified TI-RADS, $70.5 \%(55 / 78)$ of MTC could be categorized as "high-risk" by ultrasonic examination, while a nonnegligible portion (29.5\%) was low risk or no risk. Because l-MTC accounts for a considerable proportion of all MTC patients, a full understanding of the benign ultrasonic characteristics of MTC is vital to detect and diagnosis the lesion in earlier stage. However, some thyroid nodules indeed distinguish difficultly from benign nodule, and the underlying mechanism of formation needs further study.
Several studies have emphasized that early diagnosis of MTC is very important for surgical cure and improving prognosis $[16,17]$. The previous studies found that suspicious ultrasonic characteristics were less frequence in MTC compared with PTC [4],which might lead to delayed diagnosis and treatment. Furthermore, as the previous study [12-15], about $29.5 \%$ of MTC were classified as l-MTC in our study. So, measurement of serum $\mathrm{Ct}$ is a another useful diagnostic tool for MTC. However, routine measurement of serum calcitonin remains controversial $[4,18-20]$, due to cost-effective problem and the low prevalence of the disease. As a clinician, I think that the costs of detecting one MTC patient are quite reasonable by routine measurement of $\mathrm{Ct}$, compared to the potential costs of missing the diagnosis of this treatable malignancy, even prognosis or life. In our hospital, routine measurement of serum $\mathrm{Ct}$ is recommended by most
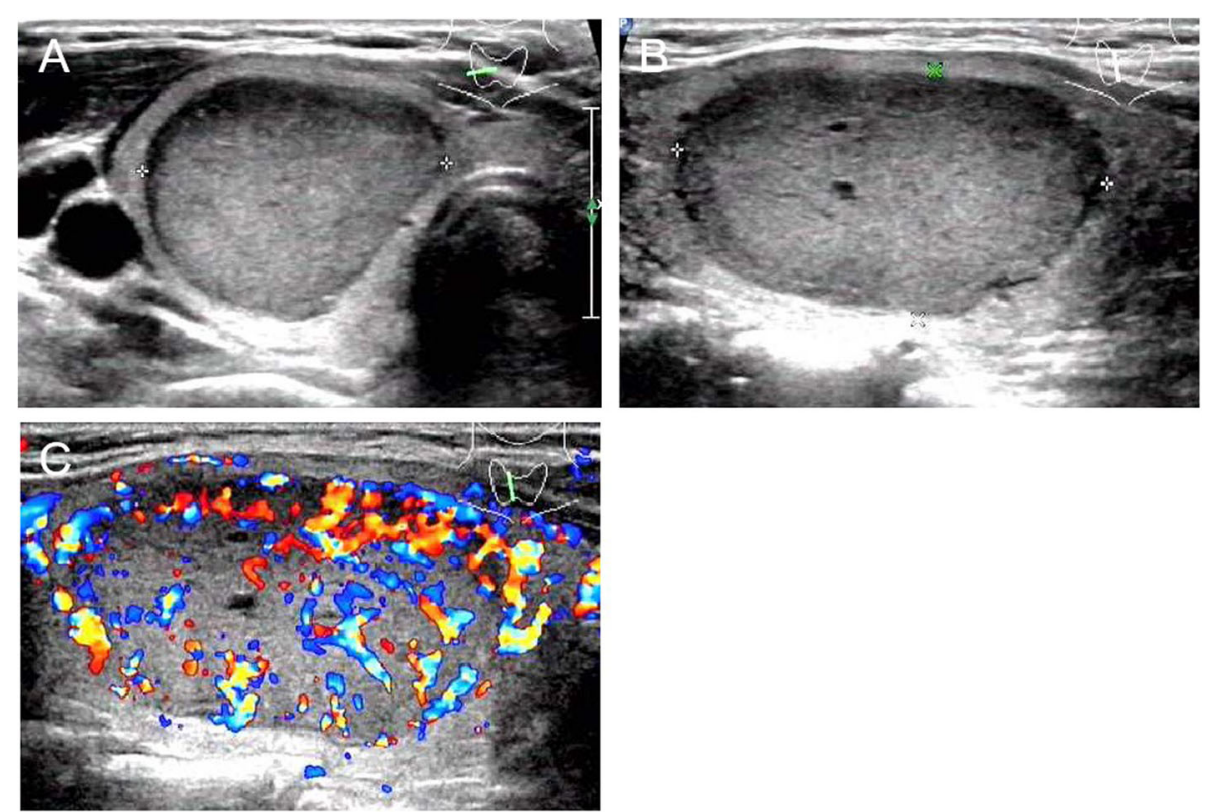

Fig. 4 US images of medullary thyroid carcinoma nodules categorized by TI-RADS 2 . Female patient, 32 years old, $3.8 \mathrm{~cm} \times 2.7 \mathrm{~cm} \times 2.2 \mathrm{~cm}$. The serum calcitonin level was $>2000 \mathrm{pg} / \mathrm{mL}$. $\mathbf{a}$ and $\mathbf{b}$ Lesion was solid, iso- to hypoechoic echogenicity, well-defined, ovoid shape, small anechoic zone. a $A / T<1$. c Enhanced blood flow 

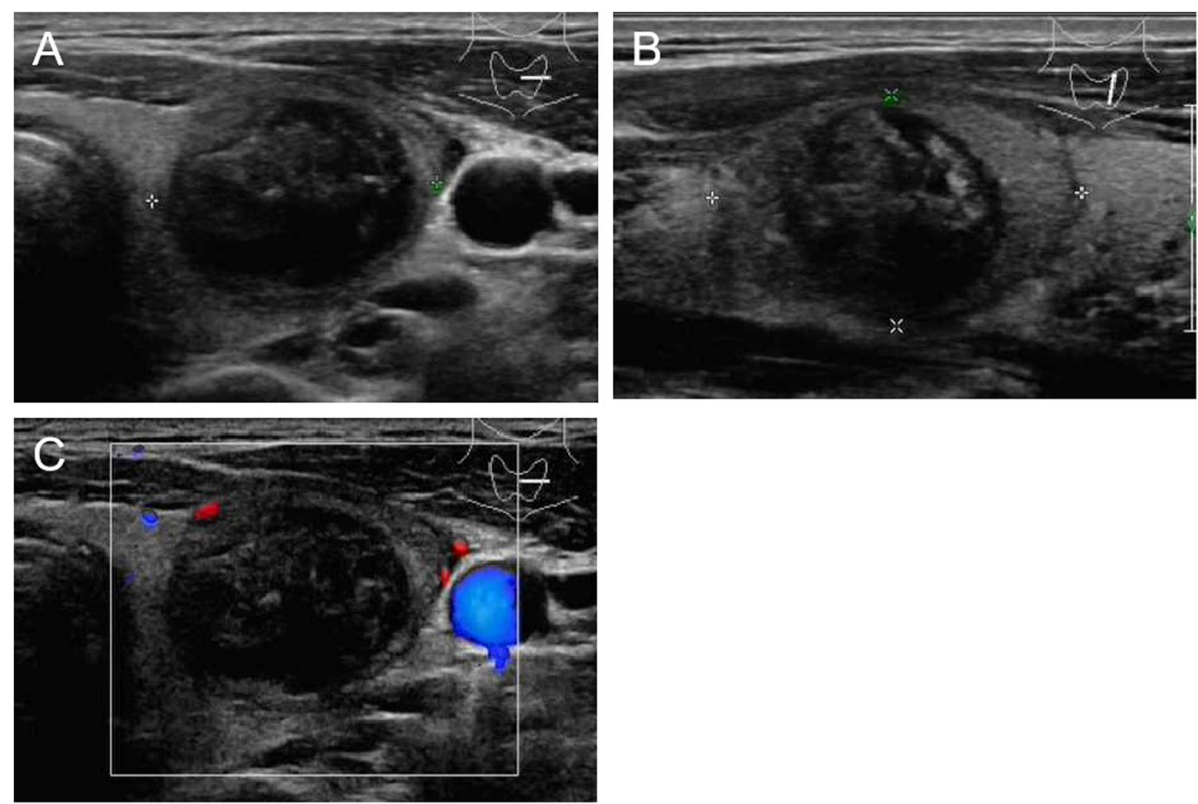

Fig. 5 US images of medullary thyroid carcinoma nodules categorized by TI-RADS 3. Male patient, 40 years old, $3.06 \mathrm{~cm} \times 2.36 \mathrm{~cm} \times 1.85 \mathrm{~cm}$. The serum calcitonin level was $<2 \mathrm{pg} / \mathrm{mL}$. a and $\mathbf{b}$ Lesion was solid, hypoechoic, ill-defined, ovoid to round in shape, microcalcifications. a A/T $<1$. $\mathbf{c}$ Absent blood flow
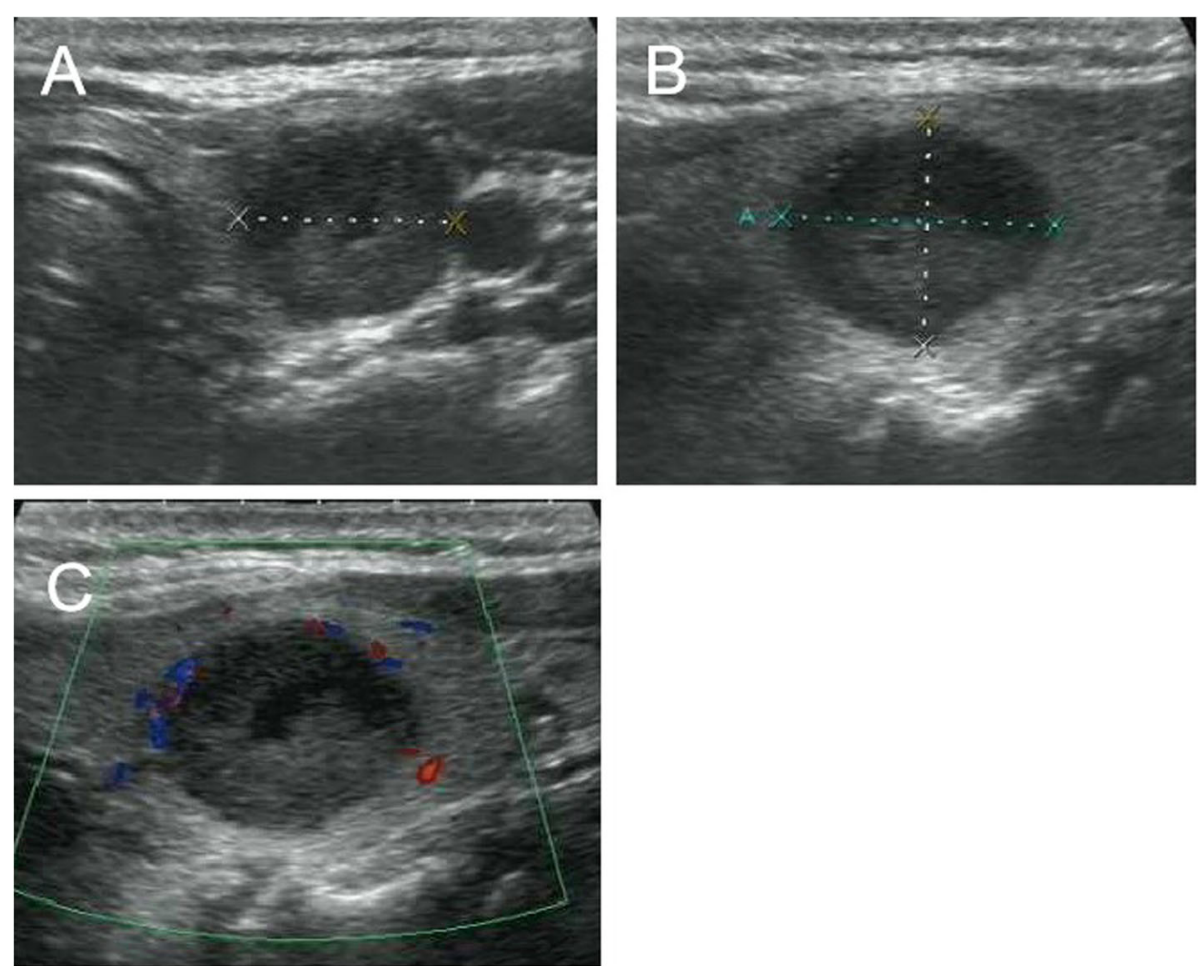

Fig. 6 US images of medullary thyroid carcinoma nodules categorized by TI-RADS 3. Female patient, 48 years old, $1.8 \mathrm{~cm} \times 1.4 \mathrm{~cm} \times 1.4 \mathrm{~cm}$. The serum calcitonin level was $960 \mathrm{pg} / \mathrm{mL}$. a and $\mathbf{b}$ Lesion was solid with a little of fluid sonolucent area, hypoechoic, well-defined, ovoid to round in shape. a $A / T<1$. c Absent blood flow 
clinician. In fact, routine measurement of serum $\mathrm{Ct}$ indeed plays an important role in detecting MTC in earlier stage in clinical practice. Therefore, routine measurement of serum calcitonin should be recommended in initial evaluation thyroid nodules.

Our study showed that disease recurrence was positively associated with $\mathrm{N}$ staging and negatively associated with serum $\mathrm{Ct}$ level and biochemical cure. Due to misdiagnosed as benign nodule, two patients who only underwent thyroidectomy without lymph node dissection did not show recurrence. None of 1-MTC patients relapsed, while 14 patients with m-MTC showed recurrence. As the previous study [13], disease recurrence was more frequent in m-MTC than that of l-MTC. In all, l-MTC has a more indolent biological behavior than m-MTC. Regarding disease recurrence, extrathyroid extension and biochemical cure were independent risk factors for recurrence of MTC.

The present study has several limitations. Firstly, in view of the retrospective study, there might be inherent selection bias. Secondly, our study was performed at a single center and included a small patient population. A multicenter prospective study may be necessary. Finally, there were no genetic information in all tumor, which may lead to different growth patterns.

\section{Conclusion}

In conclusion, modified TI-RADS could predict the biological behavior of MTC. A comprehensive understanding of the ultrasonic characteristics for l-MTC is important in cases of a suspicious MTC without malignant ultrasonic characteristics. L-MTC has a more indolent character than m-MTC.The extrathyroid extension and biochemical cure were independent risk factors for recurrence of MTC.

\section{Abbreviations}

TI-RADS: Thyroid Imaging Reporting and Data System; MTC: Medullary thyroid carcinoma; Ct: Calcitonin

\section{Acknowledgements}

Not applicable.

\section{Authors' contributions}

Study concept and design: MG and SZ. JDC contributed to the data analysis. XWY performed the statistical analysis. SZ, XQZ and GWX contributed to the ultrasound data acquisition. JZZ was major contributors and contributed to writing the first draft. All authors have read and approved the final manuscript.

\section{Funding}

This study was supported by the National Natural Science Foundation of China (61875092).

\section{Availability of data and materials}

The datasets supporting the conclusion of this article available from the corresponding author on reasonable request.

\section{Declarations}

Ethics approval and consent to participate

This study was approved by the ethics committee of Tianjin Medical University Cancer Institute and Hospital, and informed consent was obtained from all patients.

\section{Consent for publication}

Written informed consent was obtained from each patient.

\section{Competing interests}

The authors declare that they have no competing interests.

\section{Author details}

1Departments of Thyroid and Neck Tumor, Tianjin Medical University Cancer Institute and Hospital, National Clinical Research Center for Cancer, Key Laboratory of Cancer Prevention and Therapy, Tianjin, Tianjin's Clinical Research Center for Cancer, Tianjin 300060, P. R. China. ${ }^{2}$ Department of Diagnostic and Therapeutic Ultrasonography, Tianjin Medical University Cancer Institute and Hospital, National Clinical Research Center for Cancer, Key Laboratory of Cancer Prevention and Therapy, Tianjin, Tianjin's Clinical Research Center for Cancer, Tianjin 300060, P. R. China.

Received: 2 April 2020 Accepted: 26 March 2021

Published online: 09 April 2021

\section{References}

1. American Thyroid Association Guidelines Task Force, Kloos RT, Eng C, Evans $\mathrm{DB}$, Francis GL, Gagel RF, et al. Medullary thyroid cancer: management guidelines of the American Thyroid Association. Thyroid. 2009;19:565-612.

2. Valderrabano P, Klippenstein DL, Tourtelot JB, Ma Z, Thompson ZJ, Lilienfeld HS, et al. New American Thyroid Association Sonographic patterns for thyroid nodules perform well in medullary thyroid carcinoma: institutional experience, systematic review, and meta-analysis. Thyroid. 2016;26(8):1093100. https://doi.org/10.1089/thy.2016.0196.

3. Kazaure HS, Roman SA, Sosa JA. Medullary thyroid microcarcinoma: a population-level analysis of 310 patients. Cancer. 2012;118(3):620-7. https:// doi.org/10.1002/cncr.26283.

4. Haugen BR, Alexander EK, Bible KC, Doherty GM, Mandel SJ, Nikiforov YE, et al. 2015 American Thyroid Association management guidelines for adult patients with thyroid nodules and differentiated thyroid Cancer: the American Thyroid Association guidelines task force on thyroid nodules and differentiated thyroid Cancer. Thyroid. 2016;26(1):1-133. https://doi.org/10.1 089/thy.2015.0020.

5. Gao M, Ge M, Ji Q, Cheng R, Lu H, Guan H, et al. 2016 Chinese expert consensus and guidelines for the diagnosis and treatment of papillary thyroid microcarcinoma. Cancer Biol Med. 2017;14(3):203-11. https://doi. org/10.20892/j.issn.2095-3941.2017.0051.

6. Na DG, Baek JH, Sung JY. Et al.Thyroid imaging reporting and data system risk stratification of thyroid nodules: categorization based on solidity and echogenicity. Thyroid. 2016;26(4):562-72. https://doi.org/10.1 089/thy.2015.0460.

7. Tessler FN, Middleton WD, Grant EG, Hoang JK, Berland LL, Teefey SA, et al. ACR thyroid imaging, reporting and data system (TI-RADS): white paper of the ACR TI-RADS committee. J Am Coll Radiol. 2017;14(5):587-95. https:// doi.org/10.1016/j.jacr.2017.01.046.

8. Yun G, Kim YK, Choi SI, Kim JH. Medullary thyroid carcinoma: application of thyroid imaging reporting and data system (TI-RADS) classification. Endocrine. 2018;61(2):285-92. https://doi.org/10.1007/s12020-018-1594-4.

9. Zhu J, Li X, Wei X, Yang X, Zhao J, Zhang S, et al. The application value of modified thyroid imaging report and data system in diagnosing medullary thyroid carcinoma. Cancer Med. 2019;8(7):3389-400. https://doi.org/10.1002/ cam4.2217.

10. Wang $X Q$, Wei $X, X u Y$, Wang $H$, Xin $X J$, Zhang $S$. Ultrasonic characteristics of thyroid nodules and diagnostic value of thyroid image reporting and data system (TI-RADS) in the ultrasound evaluation of thyroid nodules. Chin J Oncol. 2015;37:138-41.

11. Gagel RF, Hoff AO, Cote GJ. Medullary thyroid carcinoma. In: Werner and Ingbar's the thyroid. Philadelphia: Lippincott Williams and Wilkins; 2005. p. 967-88. 
12. Fukushima M, Ito Y, Hirokawa M, Miya A, Kobayashi K, Akasu H, et al. Excellent prognosis of patients with nonhereditary medullary thyroid carcinoma with ultrasonographic findings of follicular tumor or benign nodule. World J Surg. 2009:33(5):963-8. https://doi.org/10.1007/s00268009-9939-z.

13. Kim C, Baek JH, Ha E, Lee JH, Choi YJ, Song DE, et al. Ultrasoundfeatures of medullary thyroid cancer as predictors of its biological behavior. Acta Radiol. 2017;58(4):414-22. https://doi.org/10.1177/0284185116656491.

14. Choi N, Moon WJ, Lee JH, Baek JH, Kim DW, Park SW. Ultrasonographic findings of medullary thyroid cancer: differences according to tumor size and correlation with fine needle aspiration results. Acta Radiol. 2011;52(3): 312-6. https://doi.org/10.1258/ar.2010.100247.

15. Trimboli P, Giovanella L, Valabrega S, Andrioli M, Baldelli R, Cremonini N, et al. Ultrasound features of medullary thyroid carcinoma correlate with cancer aggressiveness: a retrospective multicenter study. J Exp Clin Cancer Res. 2014;33(1):87. https://doi.org/10.1186/s13046-014-0087-4.

16. Hyer SL, Newbold K, Harmer C. Familial medullary thyroid cancer: clinical aspects and prognosis. Eur J Surg Oncol. 2005;31(4):415-9. https://doi.org/1 0.1016/j.ejso.2004.11.002.

17. Pelizzo MR, Boschin IM, Bernante P, Toniato A, Piotto A, Pagetta C, et al. Natural history, diagnosis, treatment and outcome of medullary thyroid cancer: 37 years experience on 157 patients. Eur J Surg Oncol. 2007;33(4): 493-7. https://doi.org/10.1016/j.ejso.2006.10.021.

18. Haddad RI, Nasr C, Bischoff $L$, et al. NCCN guidelines insights: thyroid carcinoma, version 2.2018. J Natl Compr Cancer Netw. 2018;16(12):1429-40.

19. Gharib H, Papini E, Paschke R, et al. American Association of Clinical Endocrinologists, Associazione Medici Endocrinologi, and European thyroid association medical guidelines for clinical practice for the diagnosis and management of thyroid nodules: executive summary of recommendations. J Endocrinol Investig. 2010;33(5 Suppl):51-6.

20. Gao M, Ge M, Ji Q, et al. 2017 Chinese expert consensus on the clinical application of serum marker for thyroid cancer. Cancer biol med. 2018; 15(4):468-77.

\section{Publisher's Note}

Springer Nature remains neutral with regard to jurisdictional claims in published maps and institutional affiliations.

Ready to submit your research? Choose BMC and benefit from:

- fast, convenient online submission

- thorough peer review by experienced researchers in your field

- rapid publication on acceptance

- support for research data, including large and complex data types

- gold Open Access which fosters wider collaboration and increased citations

- maximum visibility for your research: over $100 \mathrm{M}$ website views per year

At $\mathrm{BMC}$, research is always in progress.

Learn more biomedcentral.com/submissions 